\title{
دور الإدارة الملدرسية في مواجهة ظاهرة العنف الطلابي بالمرحلة \\ المتوسطة بـالكويت في ضوء بعض المواثيق الدولية المناهضة للعنف
}

\author{
إعداد \\ د / رشاد أبو المجلد مصطفى \\ مدرس أصول التربية \\ كلية التربية بقنا جامعة جنوب الوادي \\ rashadaboelmagd@gmail.com \\ أ بندر مناحي فالح العتيبي \\ باحث لارجة الماجستير بقسم الإدارة التعليمية \\ كلية التربية بقنا - جامعة جنوب الوادي لمادي لمادي \\ bandrmanahy@gmai.com \\ أ ـ د / محمد النصر حسن محمد \\ أستاذ ورئيس قسم أصول التربية \\ كلية التربية بقنا جامعة جنوب الوادي \\ Mohamedelnasr@gmail.com \\ د / ن نسي أحمد فُؤاد \\ مدرس أصول التربية \\ كلية التربية بقنا جامعة جنوب الوادي \\ NancyAhmed@gmail.com
}




\section{دور الإدارة الملدرسية في مواجهة ظاهرة العنف الطلابي بالمرحلة المتوسطة بالكويت في ضوء بعض المواثيق الدولية المناهضة للعنف}

إعداد

د / رشاد أبو المجلد مصطفى

$$
\text { مدرس أصول التربية }
$$

كلية التربية بقنا جامعة جنوب الوادي لوني

rashadaboelmagd@gmail.com

$$
\text { أ بندر مناحي فالح العتيبي }
$$

باحث لارجة الماجستير بقسم الإدارة التعليمية

كلية التربية بقنا - جامعة جنوب الوادي لإدي

bandrmanahy@gmai.com
أ ـ د / محمد النصر حسن محمد

أستاذ ورئيس قسم أصول التربية

كلية التربية بقنا جامعة جنوب الوادي

Mohamedelnasr@gmail.com

د / ننسي أحمد فؤاد

مدرس أصول التربية

كلية التربية بقنا جامعة جنوب الوادي

NancyAhmed@gmail.com

المستخلص :

هدفت الدراسـة الحاليـة الي التعرف على دور الإدارة المدرسية في مواجهة ظـاهرة العنف الطلابي بالمرحلة المتوسطة بالكويت في ضوء بعض المواثيق الدولية المناهضة للعنف ، كما

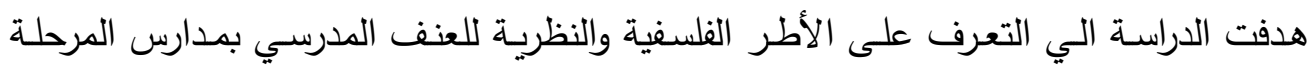
المتوسطة بالكويت. و رصد واقع العنف المدرسي بمدارس المرحلة المتوسطة في دولة الكويت من وجهة نظر الطلاب ، كما تتوصل الدراسـة الي وضع تصور مقترح لتطوير دور الإدارة

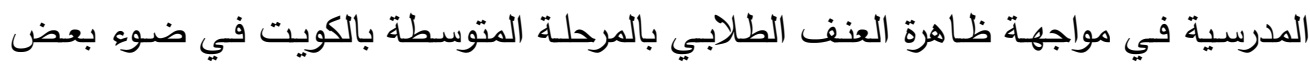

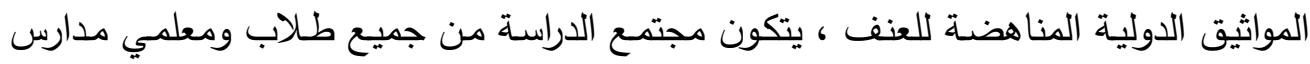

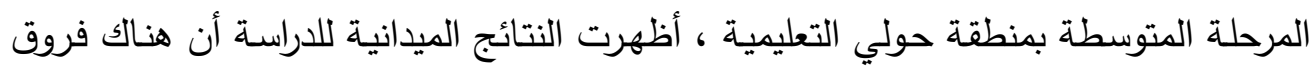
ذات دلالة احصائية بين متوسط المحاور المختلفة التي تقيس ظاهرة العنف الطلابي من حيث الته القبول في جميع المجالات. الكلمات الافتتاحية : الادارة المدرسية - العنف الطلابي - المواثيق الدولية . 


\title{
The role of school administration in facing the phenomenon of student violence in the middle stage in Kuwait in the light of some international conventions against violence
}

\author{
Prof. Dr: Mohamed EI Nasr Hassan \\ Department of Education \\ Faculty of Education, Qena \\ South Valley University \\ Mohamedelnasr@gmail.com
}

\author{
Dr. Rashad Abou EIMagd Mostaf \\ Teacher of pedagogy \\ Faculty of Education, Qena \\ South Valley University \\ rashadaboelmagd@gmail.com
}

\section{Dr. Nancy Ahmed Fouad \\ Teacher of pedagogy \\ Faculty of Education, Qena \\ South Valley University \\ NancyAhmed@gmail.com}

\author{
Bandar Menahi Faleh Al - Otaibi \\ Faculty of Education, Qena \\ South Valley University \\ bandrmanahy@gmai.com
}

\begin{abstract}
:
The present study aimed to identify the role of school administration in facing the phenomenon of student violence in the middle stage in Kuwait in the light of some international conventions against violence, And the study aimed to identify the philosophical and theoretical frameworks of school violence in middle schools in Kuwait. And monitor the reality of school violence in middle schools in the State of Kuwait from the point of view of students, and the study to develop a proposed vision to develop the role of school administration in the face of the phenomenon of student violence in the middle stage in Kuwait in the light of some international conventions against violence, The study population consists of all the students and teachers of the intermediate schools in Hawally. The field results showed that there are statistically significant differences between the average of the different axes that measure the phenomenon of student violence in terms of acceptance in all fields .
\end{abstract}

Keywords : The school administration - Student violence - International Agreements 
تزايد انتشار ظاهرة العنف في الآونة الأخيرة في غالبية المجتمعات العالمية ، بحيث أصبحت ظاهرة تهاد كيان العديد من هذه المجتمعات وأمنها، حيث شهدت المدارس الكويتية، بما في ذلك مدارس تهاس المرحلة المتوسطة، زيادة في تكرار هذه الظاهرة السلبية، مما يعكر صفو المدارس وأمنها، وأحياناً يبعدها عن التركيز على أهدافها التربوية، والعمل على التصدي لهذه الظاهرة. (احد ، ^ . . ؟) حيث إن التصدي لظاهرة العنف ـ وبخاصة الددرسي • إحدى القضايا المهمة والملحة التي يجب أن يتبناها المجتمع الدولي، والدول، والمؤسسات الحكومية والأهلية بكل حزم وإصرار.

ويأتي العنف على أثكال عدة وبدرجات مختلفة، وأكثر أثكال العنف ظهوراً بين الأفراد هي العنف اللفظي والجسدي، والنشاطات المرتبطة بالجنس، وتدمير الممتلكات. حيث ذكرت منظمـة الصحة العالمية r . . r ثلاثة أثكال للعنف، وقسمت العنف إلى ثلاث مجموعات بحسب خصائص مقترفي فعل العنف وهي: العنف الموجه للذات، والعنف الموجهه من قبل الآخرين نحو العائلة أو الأقران، والعنف الجمـاعي الذي يمـارس ضـمن جماعـات ترتبط بعوامـل العشيرة ،أو الأحزاب، أو العرق.

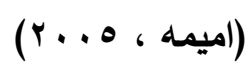

ويأخذ العنف الددرسي أشكالاً مختلفة منها الجدي، والمنطوق، والمكتوب مثل: العنف الجسدي وهو استخدام القوة الجسدية بثكل متعدد لإيذاء الآخرين وإلحاق الضرر بهم، والعنف اللفظي والذي

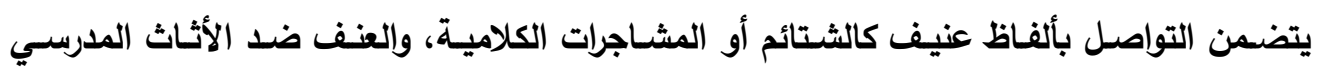
ومرافق المدرسة، والعنف النفسي، والعنف الجنسي. كما تتعدد أسباب ظاهرة العنف المدرسي فقد تكون للتعبير عن الذات ولفت الانتباه، أو بسبب ظروف مجتمعية وأسرية، أو أثير وسائل الإعلام

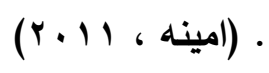

حيث تعد المرحلة المتوسطة مرحلة متميزة من مراحل نمو المتعلمين إذ تقع عليها تبعات أساسية وذلك للوفاء بحاجاتهم ورغباتهم وتطلعاتهم وهي بحكم طبيعتها في السلم التعليمي تقوم بدور تربوي

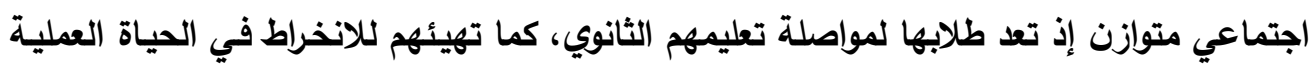

$$
\text { العدد الأريعوذة }
$$


من خلال الكثف عن ميولهم واستعدادهم وقدراتهم والعمل على تنمية تلك القدرات بما يساعدهم على اختيار الاراسة التي تناسب خصائصهم •

\section{مثكلة البحث}

تواجه مدارس المرحلة المتوسطة ارتفاعاً ملحوظاً في انتثار ظاهرة العنف نتيجة للعديد من العوامل الاقتصـادية الاجتماعيـة، والسياسـية، وعوامـل التطـور التكنوــوجي، والعولمــة والانفتـاح وامتـزاج الثقافات. وقد لوحظ في الآونـة الأخيرة تزايد في تفشي ظاهرة العنف لاى الطلبة، والتي كان لها تأثيرات سلبية على حياتهم الأكاديمية والاجتماعية والثخصية.

حيث تعد ظاهرة العنف المدرسي مشكلة عالمية تثغل اهتمام الحكومـات والمنظمـات الدولية وغير الحكوميـة، مثلمـا تثـغل أوليـاء الأمسور والمربين والطـلاب أنفسـهم. ولكن علـي رغم التأكيد علـي مناهضـة العنف المدرسي والمجتمعي علـي المستوي الدولي والمحلي، واعتبـاره انتهاكـا لحقوق الإنسـان بثكل عام وحقوق الطفل بثكل خـاص، والتوقيع علي مواثيق حمايـة الطفل ومدونات

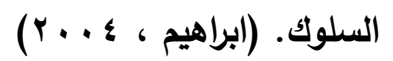

ويمكن بلورة مشكلة الدراسة في الإجابة عن الأسئلة التالية:

اـ ما الأطر الفلسفية والنظرية للعنف المدرسي بمدارس المرحلة المتوسطة بالكويت؟ r. ما الأطر الفلسفية والنظرية للإدارة المدرسية بالمرحلة المتوسطة بالكويت؟ ء. ما واقع العنف المدرسي بمدارس المرحلة المتوسطة في دولة الكويت؟

ه. مـا التصور المقترح لتطوير دور الإدارة المدرسية في مواجهة ظاهرة العنف الطلابي بالمرحلة المتوسطة بالكويت في ضوء بعض المواثيق الدولية المناهضة للعنف؟

$$
\text { أهداف البحث }
$$

1. التعرف على الأطر الفلسفية والنظرية للعنف المدرسي بمدارس المرحلة المتوسطة بالكويت.

$$
\text { العدد الأريعون }
$$




\section{r r تحليل الأطر الفلسفية والنظرية للإدارة المدرسية بالمرحلة المتوسطة بالكويت.}

r. رصد واقع العنف المدرسي بمدارس المرحلة المتوسطة في دولة الكويت من وجهة نظر الطلاب. ؛ ـ وضع تصور مقترح لتطوير دور الإدارة المدرسية في مواجهة ظاهرة العنف الطلابي بالمرحلة المتوسطة بالكويت في ضوء بعض المواثيق الدولية المناهضة للعنف.

\section{أهمية البحث}

أ) تتناول موضوعا في غاية الأهمية وهو العنف المدرسي، وكونه من المشكلات التي يجب دراستها والتعرف على حجمها وإلحد من انتشارها في مدارس التعليم المتوسط بالكويت، لما لها من آثار سلبية مدمرة.

ب) انتشار مشكلة العنف المدرسي بشكل كبير في المجتمع الكويتي، وقلة الأبحاث التي تناولتها، حيث لـم يطلح الباحث إلا على دراسـة واحدة فقط في هذا المجـال اقتصرت فقط على الأطفـال المعاقين.

ت) قد تسهم الدراسـة في إرثـاد وزيادة وعي الطلاب والمربين بخطورة العنف، والذي يؤدي إلى اضطرابات سلوكية عندهم، ومن ثم التقليل من الآثار السلبية الناتجة من العنف على النواحي النفسية والاجتماعية .

ث) أهمية المرحلة العمرية التي يتناولها، وهي مرحلة المراهقة التي تعد من أهم مراحل النمو في حياة الإنسان.

ج) يمكن أن تستفيد وزارة التربية بالكويت من الاراسـة الحاليـة في تطوير سياستها الحاليـة إزاء العاملين بالتعليم المتوسط.

\section{منهج البحث}


تعتمد الدراسـة الحالية على المنهج الوصفي؛ لأنه أكثر المناهج الملائمة لطبيعة الدراسـة والذي

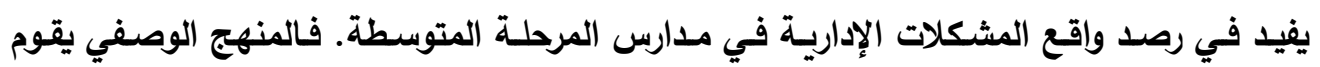
بتصور الوضع الراهن وتحديد العلاقات والاتجاهات، ووضع تنبؤات على الأوضاع المقبلة.

\section{الإطار النظري للدراسة}

الفصل الثاني : العنف الطلابي في مدارس التعليم المتوسط بدولة الكوبت مفهوم العنف

سلوك مشوب بالقسوة والعداوة والإكراه ، بعيدُ عن التحضر والمدنيـة ، تحركـه الدوافع العدوانيـة والطاقات الجسمية ، ويضر بالأشخاص أو ممتلكاتهم ، بهدف قهرهم. (بن دريدي ، V. . . Y)

وعزّف أيضاً بأنه : تعبير صارم معبر عن القوة التي تمارس لإجبار الفرد أو الجماعة على القيام بعمل أو أعمال محددة يريدها فرد أو جماعة أخرى ، كذلك فإن العنف يعبر عن القوة الظاهرة حين تتذذ أسلوباً فيزيقياً مادياً مثل الضرب أو يأخذ صورة أخرى تمثل الضغط الاجتمـاعي ، وتعتمد مشروعية العنف على اعتراف المجتمع به . ويعرٍِّ العنف المدرسي بأنه : كل فعل يتسم بالعدوانية ضد أفراد المدرسة ، ويصدر من أطراف أخرى لهم فيها سلطة ، وذلك بهدف إجبار الضحايا على تبني مواقف أو اتجاهات أو مبادئ بعيدة

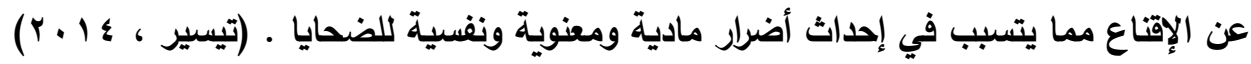
كما يعرف العنف المدرسي بأنه : " سلوك سلبي يتميز بطبيعة انفعالية شديدة غالباً ما يلجأ إليها الثخص لتأكيد ذاته بعد فثـله في تأكيدها بطرق ووسـائل أخرى ، وعادة مـا يؤدي العنف إلى

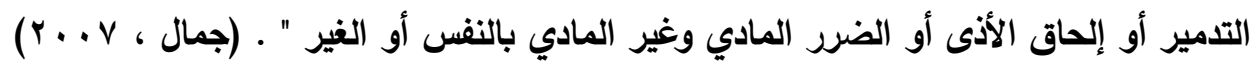
وتعرف الدراسة العنف المدرسي إجرائياً بأنه : سلوك عدواني يؤدي إلى الإضرار بالآخرين نفسياً أو جسمانياً أو لفظياً من قبل أحد أفراد المجتمع المدرسي . 


\section{موقف الإسلام من العنف}

لم يترك الإسلام جانباً من جوانب الحياة البشرية إلا وأثع علينا ينوره حتى لم يترك لأحد فيه حجة

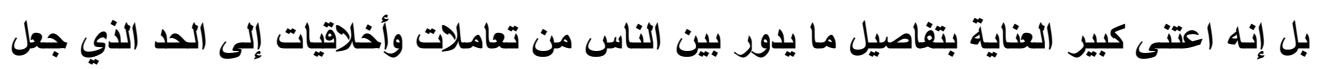

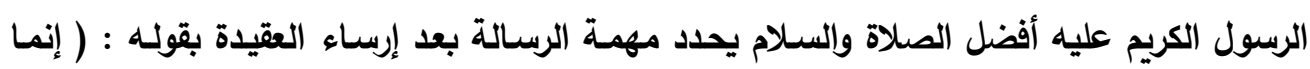
بُعثتَ لأُتمم مكارم الأخلاق).

ولا شك أن العنف المدرسي نتيجة حتمية لإنفلات الأخلاق وتهاوي القيم التي لا يمكن لدين امرئ

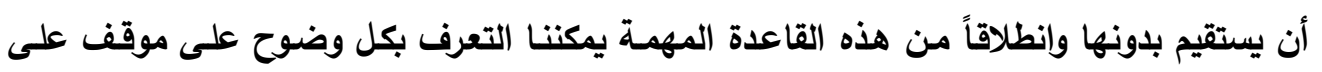
موقف الإسلام من العنف. أسباب ظاهرة العنف الطلابي في المدارس من هناك عوامل عديدة ترتبط بالعنف المدرسي منها عوامل نفسية تعلق بالفرد وعوامل مدرسية تتعلق

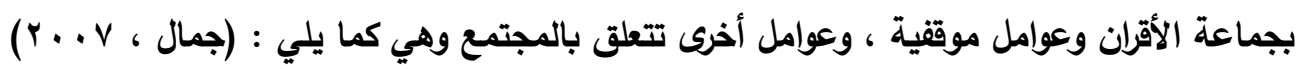
ا ـ المجتمع المدرسي والتحصيل : حيث في كثير من الأحيان يحترم الطالب ذو التحصيل الجيد ، ولا يعطى أهمية للطالب المتدني في المستوى التعليمي. r. النظام المدرسي ودوره في تنامي العنف بين الطلاب :

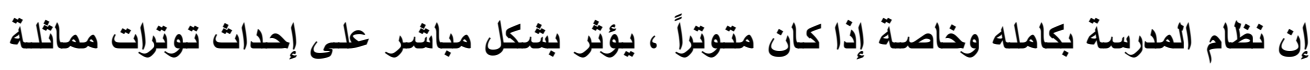

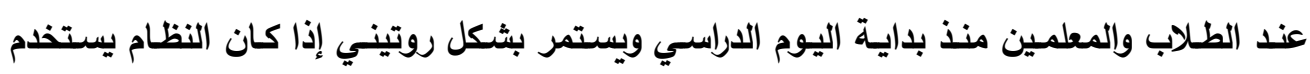
أسلوب الثدة والتعنيف . حيث أن تغير المدير ودخول مديراً آخر وبطرق تربويـة أخرى وتوجهات مختلفة عن سابقه يثير مقاومة عند الطلاب لتقبل ذلك التغيير. r. الجو التربوي المتسامع إن المدرسة التي توضح القوانين والقواعد للطلاب وتشركهم في فهمها وتحليلها والتعامل والتعايش معها بصورة مناسبة ، توفر فرصة لهم لمعرفة الطالب حقوقه وواجباته وكذلك حقوق الآخرين ـ إن استخدام الأسلوب الايمقراطي أيضاً في المدرسة قد يلاقي معارضة من قبل الطلاب الذين اعتادوا

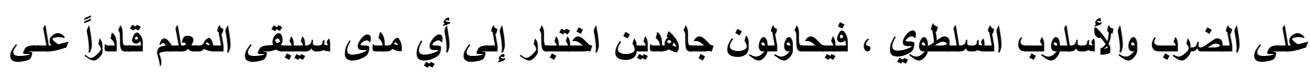

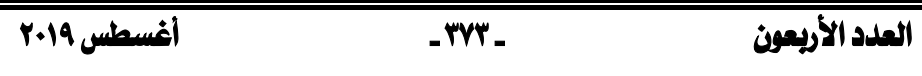


تحمل إزعاجهم وكأنهم بطريقة غير مباشرة يدعونه على استخدام العنف ، وقد ينجرف المعلم إلى هذه الرغبة مختصراً على نفسه الجها والتعب . مظاهر العنف في الوسط المدرسي

يثير جميل (ه . . r) إلى أن السلوك العنيف لاى أطفال المدارس يظهر على شكل سلوك يتضمن مظاهر مختلفة منها: ا ـ القول البذئ من سب وشتم ومنابزة بالألقاب واستخدام كلمات أو جمل للتهديد . r. إحداث فوضى في الصف او القسم عن طريق الضحك والكلام واللعب وعدم الانتباه r. الاحتكاك بالمعلم وعدم احترامه . ؛. التتففع الحاد والقوي بين التلاميذ أثناء الخروج من القسم . ه . تخريب أثاث المدرسة كالمقاعد والطاولات والكتابة على الجدران . 7. الإهمال المتعمد لنصائح المعلم وتعليماته والأنظمة وقوانين المدرسة . أشكال العنف المدرسي وأنماطه أ. أثكال العنف المدرسي كما أشار احمد الصغير إلى أن العنف الطلابي يأخذ أثكالاً متعددة هي : ا ـ الإضراب والامتناع عن الدرس : حيث يتزعم بعض الطلاب حركـة العصيان والإضراب داخل المدرسة ، وقد يكون هذا الإضراب على نطاق ضيق فيثمل عدداً من طلاب الفصل الواحد ، أو على نطاق واسع فيشمل مجموعة من الطلاب من مختلف الفصول ـ وهذا العصيان والإضراب إنما يعكس رغبة الطلاب في العدوان على النظام المدرسي ومصدر السلطة في المدرسة . (جميل ، (r...

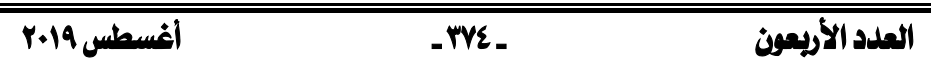


r. الإتلاف والتحطيم : حيث يقوم بعض الطلاب بالعدوان المادي على بعض أجهزة ومعدات وأثاث

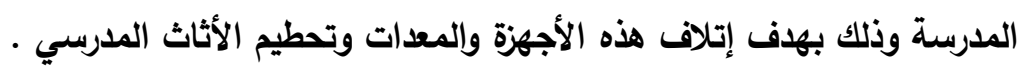

r. العدوان الموجه إلى الآخرين : يقوم بعض الطلاب بإثارة الثغب داخل المدرسة أو داخل حجرات

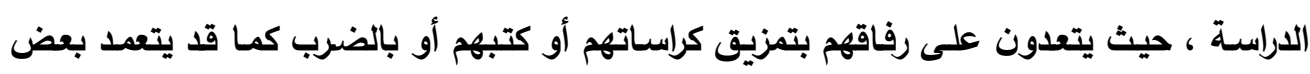
الطلاب إلى إثاعة جو من الفوضى داخل حجرات الدراسة وذلك بالتعدي على زملائهم وربما يتطور الأمر إلى التعدي على معلميهم في المدرسة . ء. التمرد على المجتمع المدرسي : هو تجمع بعض الطلاب في عصابات أو شلل تحاول الخروج

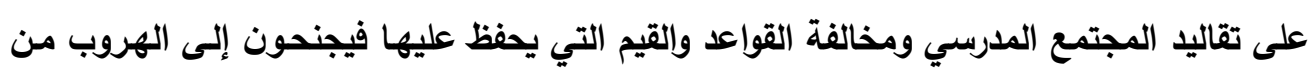
المدرسة وإلى تعاطي المخدرات والتدخين والجنس والتعدي على الآخرين خارج المجتمع المدرسي .

أنواع العنف الطلابي ومظاهره ومحاوره أ. أنواع العنف

1 ا ـ عنف من خارج المدرسة

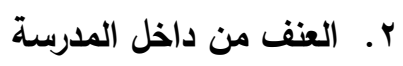

تلخص الدراسة أشكال العنف المدرسي فيما يلي :

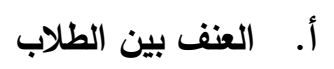

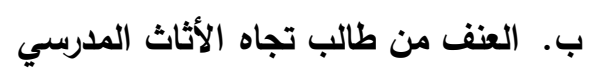
ت. العنف من طالب تجاه المعلم أو الإدارة المدرسية العندية

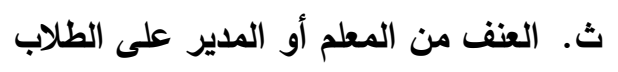
النظريات المفسرة للعدوان والعنف المدرسي أصبح العدوان يثكل في عصرنا سبباً هامـاً من الأسباب أزمات الإنسان ومصائبه ، وبالرغم من

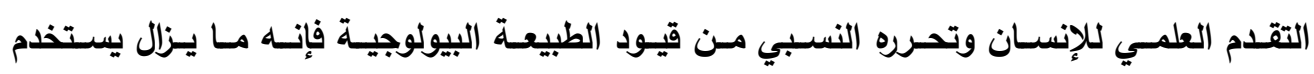


ميكانيزمات تكيفية مستمدة من تاريخه الطويل منذ وجد على سطح الأرض تتضمن نماذج بدائية من العدوان والعنف والميل إلى المشاغبة ، بينما كانت تلك الميكانيزمات هي الاستجابات الأكثر

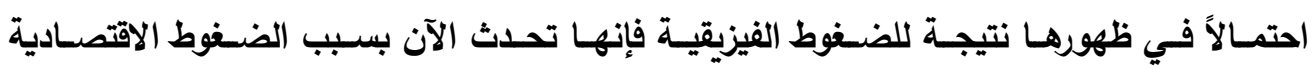
والاجتماعية وبينما استخدم السلوك العنيف للمحافظة على بقاء النوع البثري في أوقات الخطر

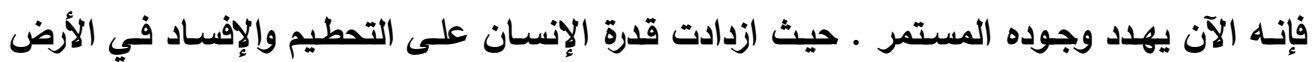

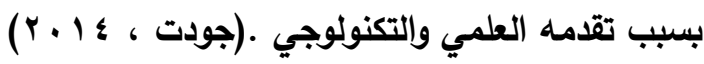
أطراف العنف المدرسي تواجه المدرسة الحديثة تزايداً في ظاهرة العنف والعدوان بين الطلاب ، وبين الطلاب والمعلمين ، فما هو المقصود بالعنف ؟ العنف هو كل تصرف يؤدي إلى تزايد في إلحاق الأنى بالآخرين ، وقد يكون جسدياً أو نفسياً . فالسخرية والاستهزاء من الفرد وفرض الآراء بـالقوة وإسـماع الكلمـات

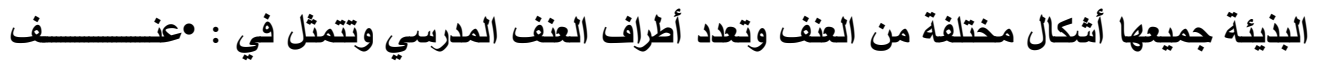

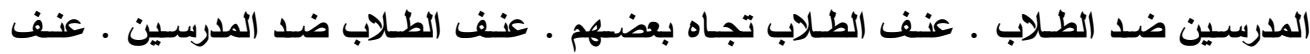
المدرسين ضـد بعضهم . عنف الأثـخاص ضـد الممتلكـات العامـة والخاصـة ـ عنـف مـن خـارج المدرسة.

الفصل الثالث : دور إدارة مدارس المرحلة المتوسطة بالكويت في مواجهة العنف الطلابي

مدارس المرحلة المتوسطة بالكويت 
تقع دولة الكويت في الركن الثمالي الغربي للخليج العربي الذي يحدها من الثرق ، حيث يحدها

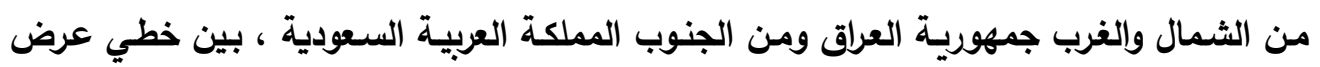

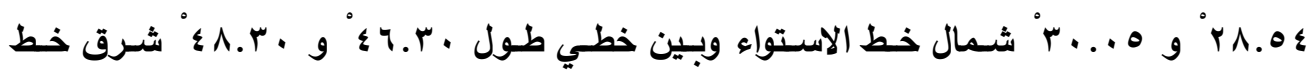

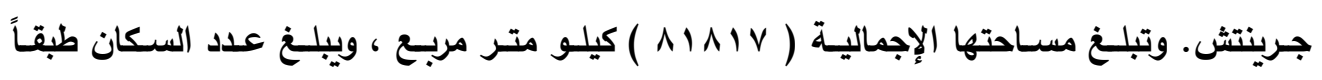

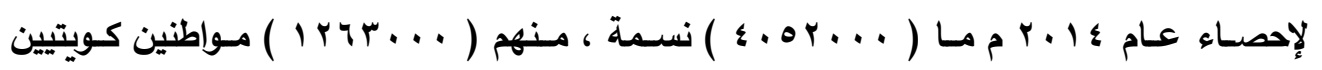

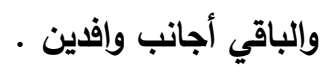

إدارة مدارس المرحلة المتوسطة بالكويت 1- سياسات المرحلة المتوسطة بالكوبت

قطعت دولة الكويت شوطاً كبيراً في تطوير النظام التعليمي وذلك من خلال تعميم التعليم وإلزاميته لجميع المواطنين الكويتين ، وزيادة حجم الإنفاق التعليمي ورفع مستوى الكفاية الخارجية للنظام

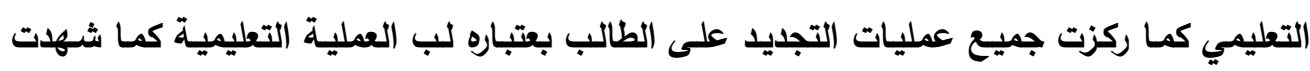
المؤسسات التعليمية ـ على اختلاف مستوياتها ـ بعض التجديدات والتطورات على المستوى الفردي والمؤسسي ، التي تساعد هذه المؤسسات بدورها على التكيف مع متطلبات العصر الحالي. (حليمه (r. Ir ،

r- نظام المرحلة المتوسطة بالكويت

تُعد المرحلـة المتوسطة بالكويت نظامـاً تعليمياً يـوفر الأسـاس لإعداد النشع في وحدة منهجيـة

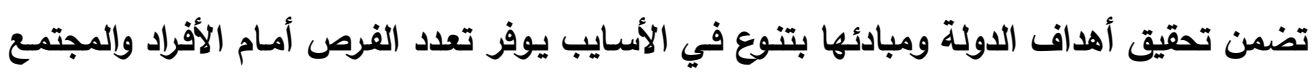
لتنمية مهاراتهم وقدراتهم. دور المدرسة في مواجهة العنف الطلابي استراتيجيات مواجهة العنف الطلابي

يعتبر التذخل المبكر وسيلة ناجعة للد من العنف المدرسي و التقليل من الآثار السلبية المترتبة

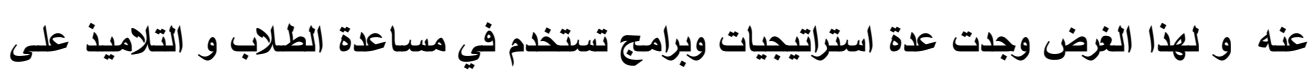


خفض العنف في الددرسة ، و معظم هذه البرامج و الاستراتيجيات تتطلب تضافر الجهود بين إدارة

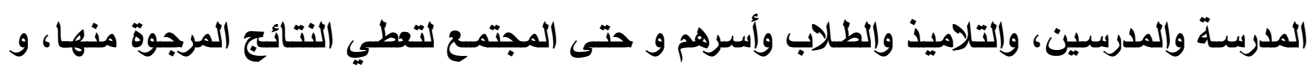
فيما يلي عرض لبعض الاستراتيجيات و البرامج التي تم اقتراحها وبناء ها في هذا المجال. (حيدر ، $(r \cdot 10$

الدور المشترك بين المرشد الطلابي وبين إدارة المدرسة تجاه ظاهرة العنف الطلابي : عند ظهور علامات العنف لاى طلاب المدرسة، فمن المتوقع أن تقوم المدرسة بدورها لمعالجة هذا العنف، لاسيما وأنـه سينعكس حتمـاً على مستوى الطالب الدراسـي والذابي هو محور عمل إدارة المدرسة.

إن دور إدارة المدرسة تجاه العنف الطلابي يعد غاية في الأهمية كونها تمثل رأس الهرم التعليمي داخل المدرسـة وباستطاعتها تنظيم العمل وتوزيع المهمـات، وجعل طاقم الإداريين والمعلمين في خندق واحد مع المرشد الطلابي لمواجهة العنف الطلابي. دور مدير المدرسة في مواجهة العنف الطلابي نظرا لما يترتب عن العنف المدرسي من مشكلات و آثار لاى كل أطراف العملية التربويـة، كان من الواجب البحث في طرق من شانها أن تقلل من العنف ومخلفاته، ويمكن تلخيص هذه الطرق فيما

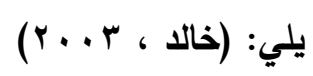

• ضرورة فهم الأستاذ لطبيعة المرحلة التي يمر بها التلاميذ في فترة المراهقة وإقامة تربصات تكوينية تركز على دراسة علم النفس النمو للمراهق ودراسة بيداغوجية التدريس. . تفعيل دور جمعية أولياء التلاميذ لمتابعة أبنائهم وتنسيق عملها مع المدارس.

• توفير أخصائيين نفسانيين بالمؤسسات التعليمية لمساعدة التلاميذ على تجاوز مشكلاتهر. الفصل الرابع : الإطار المنهجي للدراسة 
أن هناك علاقة معنوية ذات دلالة إحصائية بين المحاور المختلفة التي تقيس دور الإدارة المدرسية

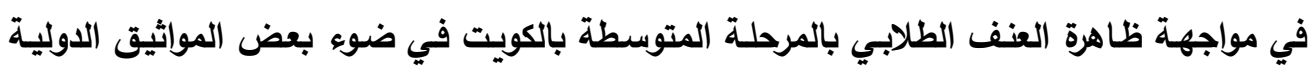
المناهضة للعنف. المحور الاول : دور ادارة المدرسة تجاه ظاهرة العنف الطلابي المحور الثاني : دور المعلم في مواجهة ظاهرة العنف الطلابي المحور الثالث : دور الاخصائي في مواجهة ظاهرة العنف الطلابي طرق البحث : - مرث

يصف هذا الفصل ويناقش منهجية البحث المستخدمة لإنجاز أهداف البحث المقترحة في الفصل الأول. يبدأ بعرض موجز لأهداف البحث. يوضـح هذا الفصل أيضًا عمليـة اختيار حجم السكان والعينـة المستخدمة في هذه الدراسـة البحثية. كمـا يصف عمليـة جمـع البيانـات ، ويوضـح هيكل وتظوير استبيان البحث.

هيكل الدراسة التطبيقة ( الميدانية )

يتناول هذا الفصل الجزء التطبيقي والعملي بالبحث، والذي سوف يتم من خلاله دراسـة وتحليل النماذج المختارة بمنطقة الدراسة ، لتطوير دور الادارة المدرسية في مواجهة ظاهرة العنف الطلابي بالمرحلة المتوسطة بالكوبت في ضوء بعض المواثيق الدولية المناهضة للعنف.

المواد

تضمن هذا البحث عدد من الطرق وأدوات البحث المختلفة حيث تم استخدام الجانب النظري في البحث من خلال استعراض المراجع السابقة من الكتب والدوريات والمقالات التي تناولت دور الإدارة المدرسية في مواجهة ظاهرة العنف الطلابي بالمرحلة المتوسطة بالكويت في ضوء بعض المواثيق الدولية المناهضة للعنف. كما تم استخدام الجانب التطبيقي والذي تمثل في استخدام اداه من أدوات البحث العلمي والتي تتمثل في استمارات استقصاء كذلك المعلمين القائمين علي عملية التدريس. دراسة أولية حول المدارس التي تم التحقيق فيها: 
بثكل أولي ، أجرى الباحث مسحًا على عينة البحث (مداس المرحلة المتوسطة بالكويت). يهدف

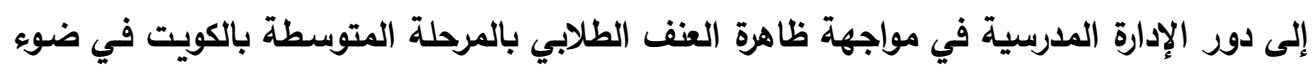
بعض المواثيق الدولية المناهضة للعنف. ركزت الدراسـة فقط على مدارس منطقة حولي بالكويت.

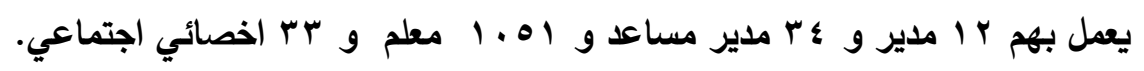

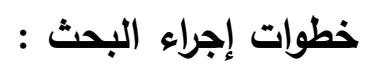

ا- تم الإطلاع علي الدراسات والمراجع العربية والأجنبية الحديثة التي تتعلق بمجال الاراسـة قيد البحث

r- تصميم الاستمارات الخاصة بالبحث من حيث المحاور والعبارات . ؟ - عرض الاستمارات علي الخبراء للوصول إلي الثكل النهائي لها . ه - تطبيق الاستمارات في صورتها النهائية علي عينة البحث . צ- تجميع الاستمارات وتفريغ البيانات .

v استخدام المعالجات الإحصائية المناسبة لتحويل البيانات الرقمية إلي بيانات لفظية . - 1- مناقشة وعرض النتائج · محتويات الاستبيان: - n

وقد تم تقسيم الاستبيان الي ثلاثة اجزاء رئيسية:

الجزء الاول: يثمل البيانات الثخصية مثل النوع , الصفة والمنطقة التعليمية .

الجزي الثاني: عباره عن سؤالين: العؤال الاول : هل دور المدرســة واضـح في مواجهة العنف الطلابـي بمـارس المرحلـة المتوسـة بالكويــــ ؟ والسـؤال الثـاني : هـل هــاتك توجيـه مـن ادارة المدرسة المتوسطة بالكويت في المساعدة على القضاء على مشكلة العنف الطلابي؟ 
الجزي الثالث : تم استخدام الأسئلة المفتوحة بالإضـافة إلى مقيـاس ليكرت المكون مـن ثلاثـة مستويات والذي يتـراوح مـن ا "لا" إلى ؟ "تعم" لتصـيم استمارة الاستبيانات. يشـمل المحساور المختلفة التي تقيس دور الادارة المدرسية في مواجهة ظاهرة العنف الطلابي بالمرحلة المتوسطة بالكويت في ضوء بعض المواثيق الدولية المناهضة للعنف.

الفصل الخامس : مناقشة وتحليل نتائج الدراسة

(Study Instrument reliability) دراسة الصدق والثبات

Cranach alpha للتأكد مـن الموثوقيـة لجميع البيانـات تـم استخدام معامل الفـا Correlation مقبولا في معظم الحالات للعلوم الاجتماعية. تم حساب الثقة والثبات باستخدام معامل الفا واظهرت الاختبارات ان معاملات الثبات لجميع البيانات كانت فوق • V. . مما يدل علي انها اداه موثوق بها ليتم استخدامها كما هو موضح بالجدول رقم ( )

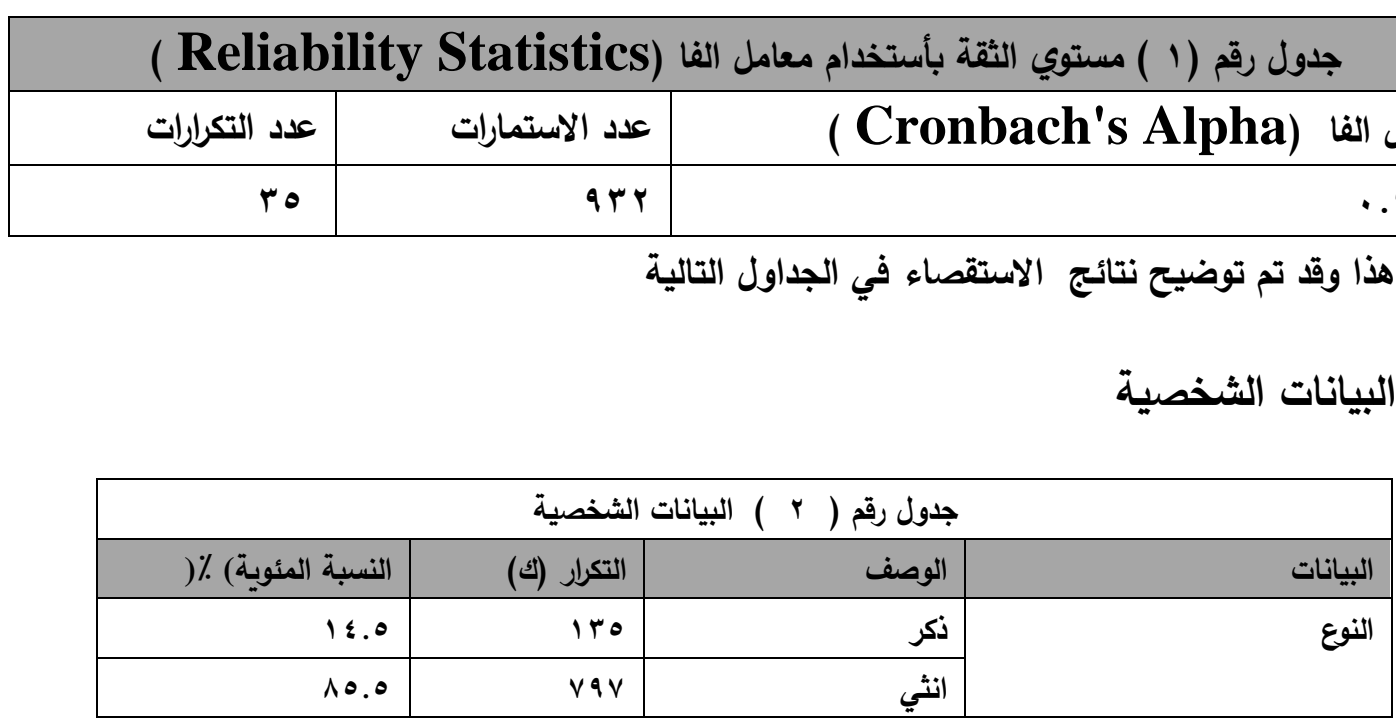




\begin{tabular}{|c|c|c|c|}
\hline $1 \ldots$ & arr & الاجمالي & \\
\hline qr.r & 199 & معلم & \multirow[t]{4}{*}{ الصفة } \\
\hline r.q & rv & اخصائي اجتماعي & \\
\hline$r .9$ & чq & مدير او مساعد & \\
\hline $1 \ldots$ & qrr & الاجمالي & \\
\hline
\end{tabular}

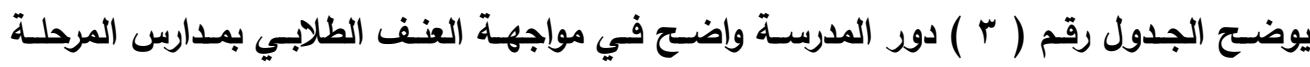

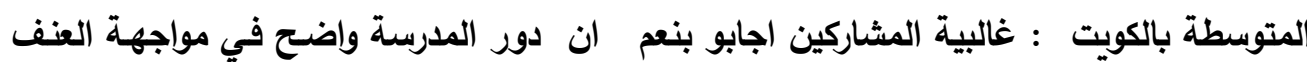

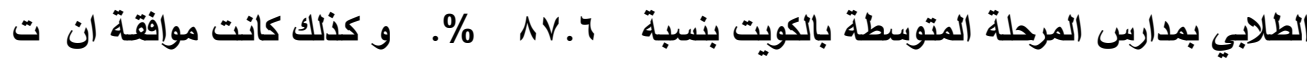
هناك توجيه من ادارة المدرسة المتوسطة بالكويت في المساعدة على القضاء على مشكلة العنف

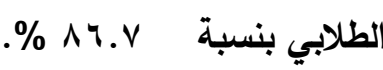

\begin{tabular}{|c|c|c|c|c|}
\hline & & & & جدول رقم ( r ) \\
\hline المئوية & التكرار & |الاجابه & الكود & السؤال \\
\hline AV. & 114 & نعم & \multirow{3}{*}{ س1 } & \multirow{3}{*}{ العنف الطلابي بمدارس الاول : دور المدرسة واضح في مواجهة المتوسطة بالكويت } \\
\hline IY. & 117 & $y$ & & \\
\hline $1 \ldots$ & arr & الاجمالي & & \\
\hline งั. & $\Lambda \cdot \Lambda$ & نعم & \multirow{3}{*}{ س2 } & \multirow{3}{*}{ 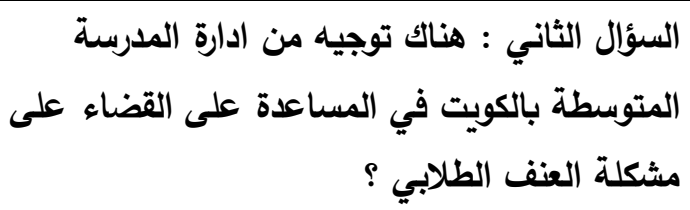 } \\
\hline Ir.r & Irs & $y$ & & \\
\hline $1 \ldots$ & arr & الاجمالي & & \\
\hline
\end{tabular}

يوضح الجدول رقم ( ؛ ) ترتيب محاور الاستبيان التي تقيس ظاهرة العنف الطلابي داخل مدارس المرحلة المتوسطة بالكويت و من جداول البيانات يلاحظ أن:

بالنسبة للمحور الاول : دور إدارة المدرسة تجاه ظاهرة العنف الطلابي غالبية المشاركين راضين على معظم العناصر وكان ترتيب هذه العناصر كالتالي: 
ا. جاء في المركز الاول يقوم المدير بتهيئة البيئة والظروف المناسبة التي تساعد في تحقيق

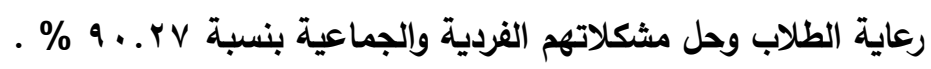

r. . تلاه في المركز الثاني تسعى إدارة المدرسة لحل مثكلات العنف المدرسي التي تحدث داخل

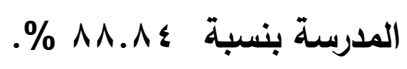

r. ت تلاه في المركز الثالث ان للعنف اللفظي داخل المدرسـة سبب للعنف بين الطلاب بنسبة

$$
\% \wedge \wedge .1 \%
$$

؛. . ونجد ان المركز الرابع ان للعنف اللفظي داخل المدرسـة سبب للعنف بين الطلاب بنسبة

$$
\text { \%^ . } 9 \wedge
$$

ه. تلاه في المركز الخـامس التعرض للعنف داخل المدرسـة يسبب العنف الطلابي بنسبة

$$
\text { \%^ฯ.v. }
$$

وهذا يؤكد الموافقةعن دور ادارة المدرسة تجاه ظاهرة العنف الطلابي.

بالنسبة المحور الثاني : دور المعلم في مواجهة ظاهرة العنف الطلابي غالبية المشاركين اجابو بنعم على معم العناصر وكان ترتيب هذه العناصر كالتالي:

ا ـ جاء في المركز الاول حث المعلمين على اهمية رعاية الطلاب من خلال التعامل مـع المواقف

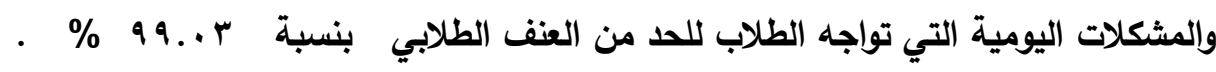
r. تلاه في المركز الثاني عند ظهور علامات العنف لاى طلاب المدرسة يقوم المعلم بمعالجة هذا

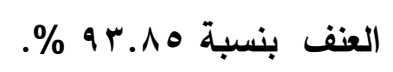
r. تـلاه في المركز الثالث يتعاون المعلم وادارة المدرسـة في التعامل مـع مشكلات الطـلاب ،

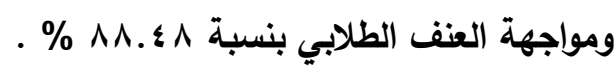
؛. ـ ونجد ان المركز الرابع الحالة المزاجية للمدرس تؤثر على استخدامه للعنف ضد الطلبة بنسبة \% ^ $1 . \wedge$. 
ه. تلاه في المركز الخامس تجد أن المعلم يوصل المـادة العلمية بطريقة تعليمية مرتبة ومرغبة

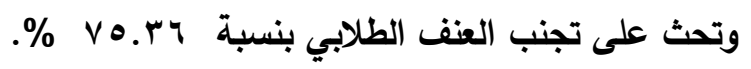
وهذا يؤكد الموافقة علي دور المعلم في مواجهة ظاهرة العنف الطلابي. بالنسبة المحور الثالث : دور الاخصائي في مواجهة ظاهرة العنف الطلابي غالبية المشاركين اجابو بنعم على معظم العناصر وكان ترتيب هذه العناصر كالتالي: ا . جـاء في المركـز الاول يقـوم الأخصـائي الاجتمـــي بحل مثـاكل العنـف الطلابـي بنسبة $\% 99.49$ r. تلاه في المركز الثاني هناك اخصائيين نفسيين بالمدرسة لمساعدة الطلاب على حل مشكلاتهم بنسبة \%9.. r. تلاه في المركز الثالث يدرك الطلاب دور الاخصائي في علاج مشكلات العنف الطلابي بنسبة \% १^.r ؛ ـ ونجــ ان المركز الرابـع تعتقد أن الإعـلام المتمثل بـالقنوات الفضـائية ومـا تطرحسه مـن أفلام الاكثن تؤثر في سلوكية الطالب بنسبة ه ه \%.v. ه. تـلاه في المركز الخامس يسـاعد الاخصائي في القضساء على ظاهرة العنف الطلابي داخل

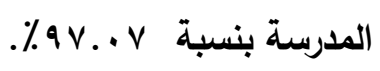

وهذا يؤكد الموافقة علي اهية دور الاخصائي في مواجهة ظاهرة العنف الطلابي. ولترتيب المحاور المختلفة التي تقيس معايير مواجهة ظاهرة العنف الطلابي بالمرحلة المتوسطة

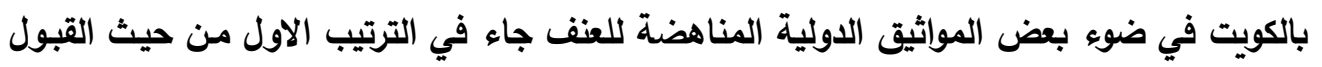

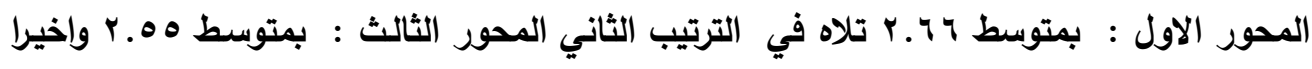
حصل علي الترتيب الثالث المحور الثاني :

\begin{tabular}{|c|c|c|c|c|c|}
\hline \multicolumn{6}{|c|}{ جدول رقم ( V ):نتائج ترتيب المحاور المختلفة التي تقيس ظاهرة العنف الطلابي } \\
\hline الترتيب & المتوسط & معدل & الانحراف & الكود & الرقم \\
\hline
\end{tabular}




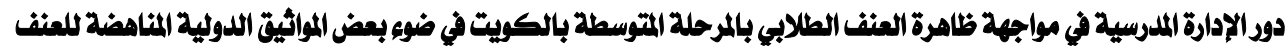

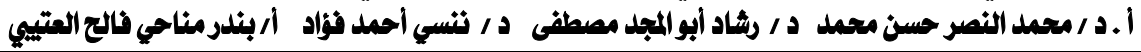

\begin{tabular}{|c|c|c|c|c|c|}
\hline & & الخطاء & المعياري & & \\
\hline$r$ & $1 . V \wedge 0$ & $\cdots 11$ & צ & 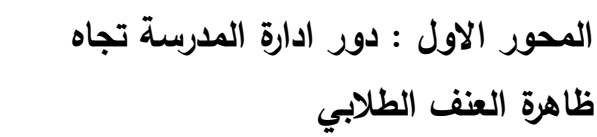 & 1 \\
\hline$r$ & $1.9 \cdot 1$ & $\ldots 1$ & .rr. & ظاهرة العنف الثاني : دور المعلم في مواجهة & $r$ \\
\hline 1 & וrr. & $\cdots \wedge$ & צrr. & ظالمحور الثالث : دور الاخصائي في مواجهة & $r$ \\
\hline
\end{tabular}

الفصل السادس : النتائج والتوصيات اولا : نتائج البحث

ا. أظهرت النتائج الميدانيـة للاراسـة أن غالبيـة افراد عينة الدراسـة هم من الاناث حيث بلغت

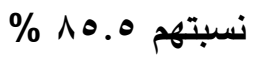

r. أظهرت النتائج الميدانية للاراسة أن غالبية أفراد عينة الدراسة هم من المعلمين حيث بلغت

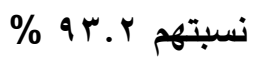

r. أظهرت نتائج الاراسة أن دور المدرسة واضح في مواجهة العنف الطلابي بمدارس المرحلة

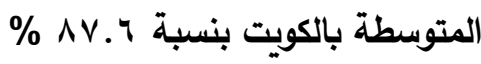

؛. أظهرت نتائج الاراسة أن هناك توجيه من ادارة المدرسة المتوسطة بالكويت في المساعدة على

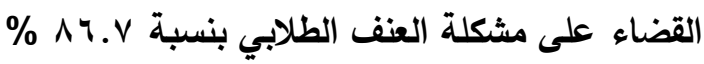
ه. أظهرت النتائج الميدانية للاراسة أن هناك دور من ادارة المدرسة تجاه ظاهرة العنف الطلابي 1. أظهرت النتائج الميدانية للاراسة أن هناك دور للمطلم في مواجهة ظاهرة العنف الطلابي V . أظهرت النتائج الميدانية للدراسة أن أهمية دور الاخصائي الاجتماعي واضح في مواجهة ظاهرة

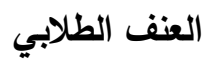

^. أظهرت النتائج العيدانية للاراسة أن هناك فروق ذات دلالية احصائية بين متوسط المحاور المختلفة التي تقيس ظاهرة العنف الطلابي من حيث القبول في جميع المجالات

العدد الأريعون


توصلت الدراسة الي مجموعة من التوصيات التالية : 1. عقد الاجتماعات من قبل إدارة الدرسة والتي تناقش من خلالها مشكلات العنف الطلابي. r. r. عقد ندوات خاصة بحالات العنف الطلابي وكيفية التعامل معها. r. اهتمام المرشد الطلابي بالدورات وورش العمل التي تعقدها وزارة التربية والتعليم.

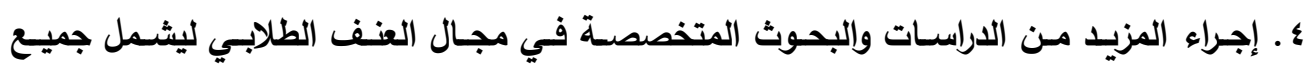

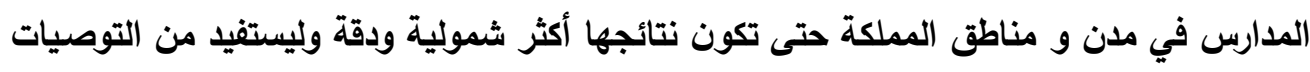
التي تخرج بها تلك الاراسات والبحوث.

ه. يجب دراسة حالات العنف لاى الطلاب دراسـة علمية من جوانب مختلفة لاستكشاف الجوانب العضوية والنفسية والاجتماعية والعمل على علاجها, وذلك عن طريق تفعيل دور المرشد الطلابي.

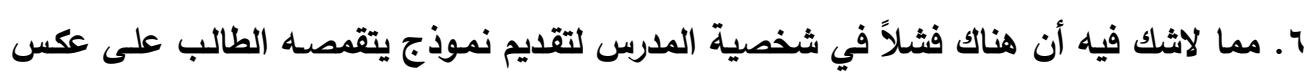

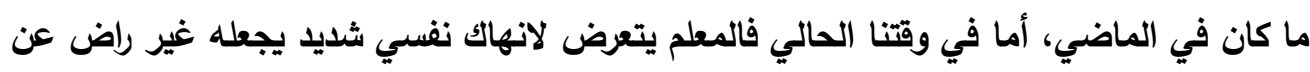
نفسد، فلابد من أعداد المعلم المختص في النواحي التربوية إلى جانب النواحي العلمية.

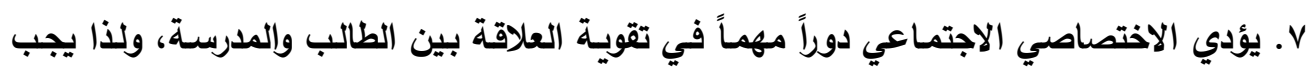

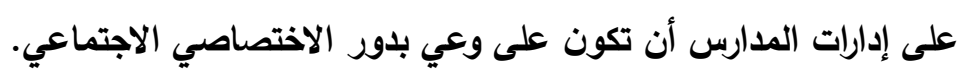

^. تحقيق التواصل بين المدرسة والبيئة: عن طريق خروج المدرسة إلى البيئة المحيطة لمواجهة بعض مشكلات البيئة المحيطة بالمدرسة وعمل التلاميذ على حل هذه المشكلات. 9 ـ التواصل المستمر بين البيت والمدرسة.

\section{مراجع الدراسة}

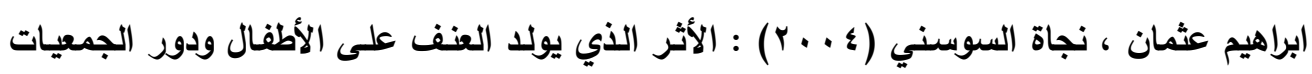

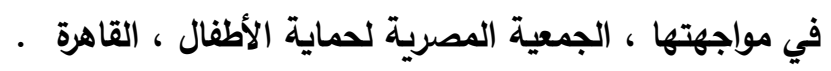

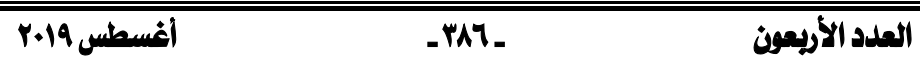




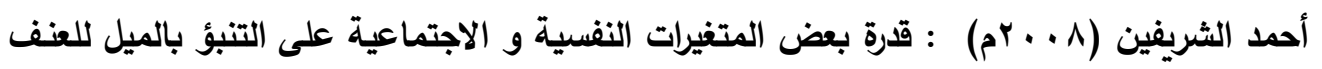

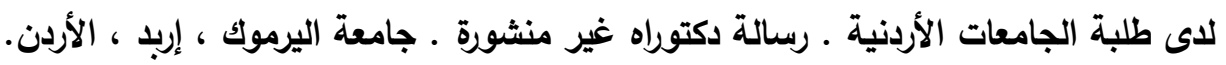

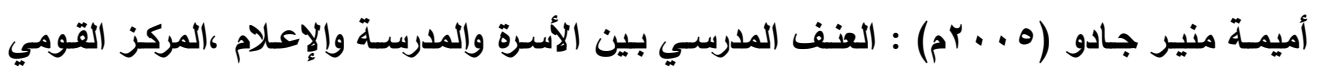

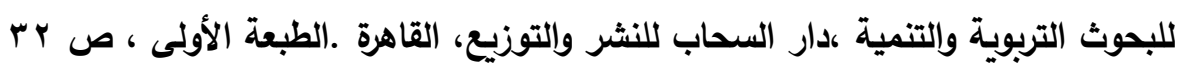

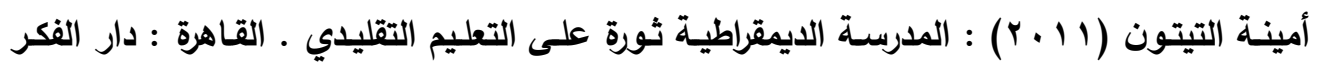

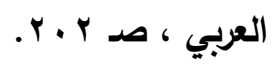

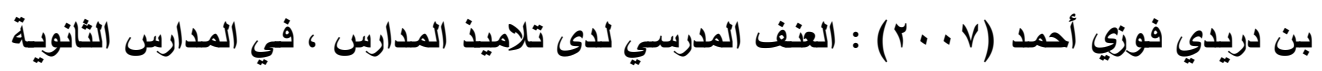

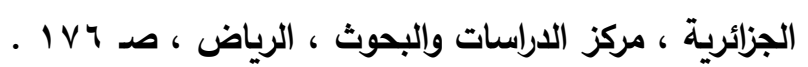

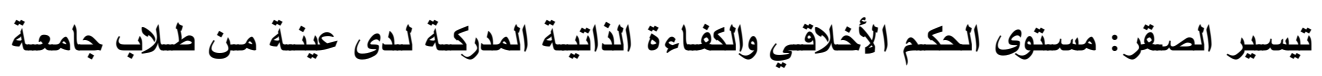

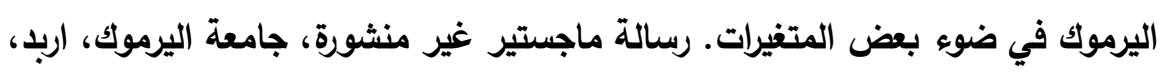

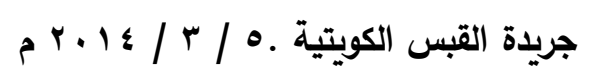

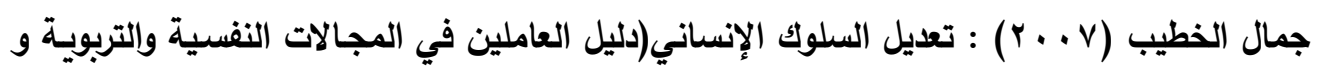

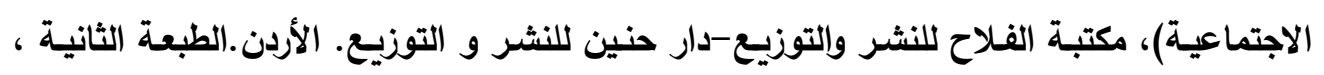
ص ص جميل نشوان(ه • . ب) : : الإدارة التربوية في ضوء الاتجاهات المعاصرة ، غزة ، مطبعة دار المنارة

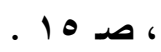

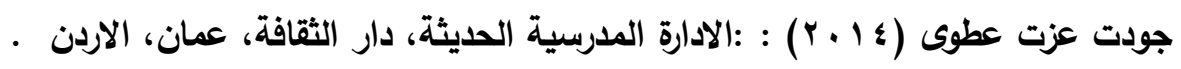

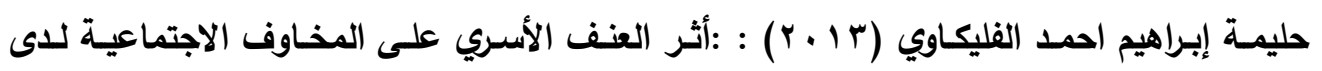

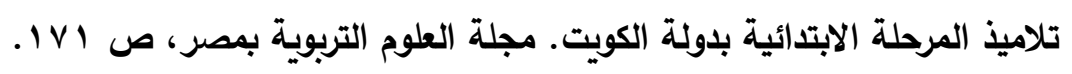

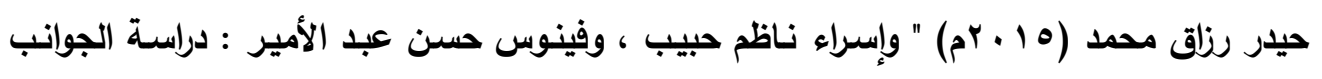

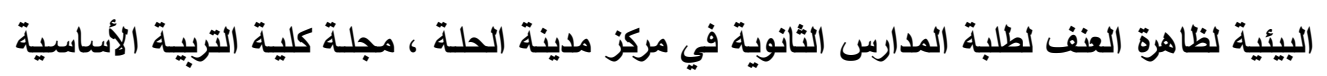

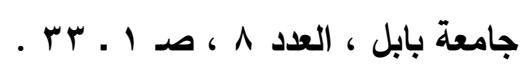

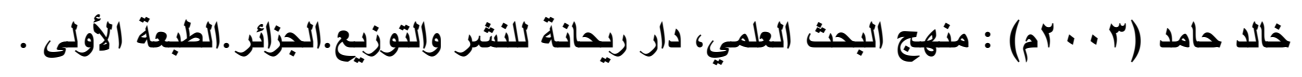

